\title{
When to Signal? The Contextual Conditions for Career-Motivated User Contributions in Online Collaboration Communities
}

\author{
Jeongsik “Jay” Lee \\ Drexel University, USA \\ j13543@drexel.edu
}

\author{
Hyunwoo Park \\ Ohio State University, USA \\ park.2706@osu.edu
}

\author{
Michael A. Zaggl \\ Aarhus University, Denmark \\ zaggl@mgmt.au.dk
}

\begin{abstract}
This paper examines the contextual conditions for users' career concern as a motivational driver of contributions in online collaboration communities. On the data of user-level activities from a computer programming-related online Q\&A community (Stack Overflow), merged with job-market data for softwaredeveloper, we find robust evidence of a positive association between individual users' career concern and their contributions. More important, we find that this positive relationship is further strengthened through the contextual conditions: the number of vacancies in the job market, the expected salaries from these jobs, and the transparency in the flow of careerrelated information within the community. We contribute to the literature on motivation in online collaboration communities. Our study thus offers insight into how career concern can be effectively utilized to motivate contributors in these communities. Our findings also foreshadow a possible paradigm change by characterizing online collaboration communities as institutions of career concern and skill signaling.
\end{abstract}

\section{Introduction}

The motivation of voluntary contributions to online communities of knowledge production and exchange has stimulated a deep interest in information systems researchers and practitioners [5,8,14,26,29,36,40,45]. One of the most relevant drivers of motivation is the starting or pushing forward of a professional career related to the community topic [30], to which we refer as career concern. For example, hobbyist product designers can kick-off a professional career by demonstrating their talent in design communities [17]. The notion of career concern as motivation is especially relevant for software developers because a large portion of their skills is difficult to observe for potential employers.

Traditionally, people's career concern and their seeking for jobs have been directly embedded into the institutions of higher education such as colleges and universities. By certifying individuals' performance in the form of degrees and diplomas, these institutions allow them to signal their job-related skills to potential employers [23,39]. We argue that crowd-based online communities of knowledge production and sharing $[5,8,14,45]$ can serve a similar role. These communities contain a large variety and depth of user skills that are often highly relevant for employers. In addition to multiple other forms of motivation [36], career concern has been shown to be an important source of motivation for making contributions to these communities [26,30], suggesting that online communities can in principle fulfill the function of institutions of career concern.

However, career concern has been treated in the literature of online collaboration communities as a largely static construct [20,26,36], with little light on the conditions for the career concern to unfold. Therefore, we study the contextual conditions that support or inhibit the contributions of career-concerned users in online collaboration communities. By shedding light on the contextual conditions, we attempt to develop an understanding of when and how career concern is more likely to unfold and stimulate contributions. Building on the labor market literature [15,16,23,38,39], we develop a framework on the contextual influences of career concern, consisting of three conditions: number of job vacancies, expected salaries, and community-market information transparency. Job vacancies are the current number of job openings in the labor market, expected salaries are the current wages associated with these vacancies, and community-market information transparency is the degree to which community members and external recruiters can observe information about each other. To empirically examine this framework, we pose the following research question: How do external job-market conditions (job vacancies and expected salary) and community-based market conditions (information transparency) shape the relationship between career motivation and user contributions in online collaboration communities?

Our empirical strategy is to utilize individual-level 
contribution data from Stack Overflow, an online collaboration community founded in September 2008. In Stack Overflow users post questions and answers (Q\&As) on computer programming-related issues for a large variety of programming languages. In particular, we exploit Stack Overflow Careers ${ }^{1}$, which is an intracommunity career service. Stack Overflow Careers allows users to post a curriculum vitae $(\mathrm{CV})$ and external recruiters to browse CVs and identify promising job candidates. Because users' achievements in the community - in the form of reputation scoresappear in their CVs, the users can signal their programming skills directly to the recruiters. Based on how much effort the users may have exerted to construct their CVs, we quantify their interest in a programmingrelated career (i.e., career concern). Moreover, the introduction of Stack Overflow Careers was an exogenous event that drastically improved information transparency in the community. To capture the contextual conditions of the market for programming jobs, we obtain data from IT Jobs Watch ${ }^{2}$, a company that tracks IT-related job advertisements in the United Kingdom. The data contain the quarterly number of job vacancies and the offered salaries in over 110 programming languages.

We find that a user's CV length-our proxy for a user's career concern-is positively related to both the quantity and quality of the user's contributions. This relationship becomes stronger when there are more job vacancies in the corresponding programming language and the expected salary from these jobs is higher. Increases in community-market transparency also positively moderates the relationship between career concern and user contribution. These results are robust to variations in the sample and estimation methods. The positive association between career concern and user contribution is particularly salient for the posts that could potentially earn more reputation points for the users. The career-motivated boost in user contribution appears to spill over to non-programming language domains as well, though the magnitude for nonprogramming language domains is smaller than for language domains, which are presumably more conducive to signaling job skills. These results are consistent with career-motivated users optimally allocating their effort to maximize returns from investing private resources.

Our study contributes to the growing literature on motivation in online collaboration communities [14] such as Q\&A sites [45], open source software development $[13,36,40]$, communities of practice $[19,21,42]$, and collaborative knowledge production [2,32]. First, we provide a framework describing the

\footnotetext{
${ }^{1}$ http://business.stackoverflow.com/careers/
}

contextual conditions for career concern to be effective. The framework reinforces the role of extrinsic motivations for contributors to online knowledge production and exchange. Specifically, we extend the current understanding of motivation based on career concern $[26,30,36]$ by the notion of community-market transparency, that is, the ease of information flow between job seekers and recruiters. Community-market information transparency suggests an effective way to utilize users' career concerns for addressing the challenges of attracting and motivating users and thereby promoting the overall viability of online communities. We also extend the literature by providing behavioral evidence based on archival data, thus overcoming the limitation of survey-based methods $[26,30,36]$ and anecdotal evidence $[22,34]$.

More broadly, our framework sheds new light on online collaboration communities by characterizing their emerging role as institutions of career-related signaling, a role that has historically been exclusive to universities and other forms of higher education. Our findings indicate strong functional resemblances of online collaboration communities to these traditional institutions $[3,23,39]$. Thus, our study challenges a conventional paradigm on institutions of career signaling: knowledge workers are now able to signal their quality and job skills without necessarily relying on the traditional signaling institutions. We submit that this new paradigm of signaling provides considerable advantages in terms of cost and accuracy. It is quite likely that online collaboration communities will play a more fundamental role as signaling institutions in the near future.

\section{Hypotheses development}

We specify our framework into several testable hypotheses (see Figure 1). We first develop a baseline hypothesis on the relationship between career concern and user contribution. We then elaborate on the three contextual conditions as moderators of this baseline.

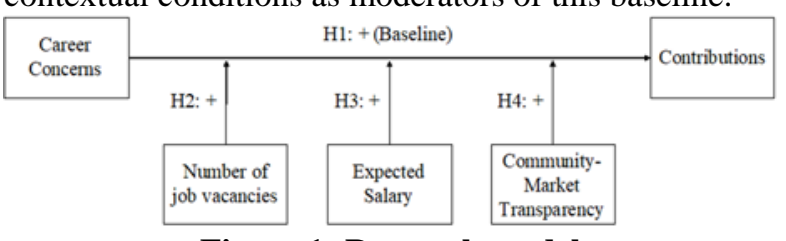

Figure 1: Research model

\subsection{Career concern and user contributions}

Most fundamentally, we expect that a significant share of community users is interested in the prospects

\footnotetext{
${ }^{2}$ http://www.itjobswatch.co.uk
} 
of entering or advancing a career related to their community activities. This form of motivation has been extensively researched in the context of open source software development [20,26,30,36] and, to a lesser extent, in other forms of online collaboration communities such as profession-specific communities of practice [42], open innovation communities [37], and Q\&A communities [43]. Users will of course vary in the degree of their career concern. Some users may be uninterested in careers but still contribute for other reasons [36], while others might have a strong inclination for career seeking. The latter, we refer to as career-concerned or career-motivated users.

The theoretical backbone for linking career concern to contribution behavior is signaling theory [23,39], which suggests that career-motivated users will try to demonstrate their otherwise-unobserved skills by contributing to their community. Here, their ability to provide costly contributions is considered as evidence for their skills. Therefore, for a baseline, we expect a positive association between a user's career concern and the level of his contributions.

Hypothesis 1 (H1): A user's career concern is positively related to the user's contributions.

\subsection{Number of job vacancies}

The number of job vacancies is the first factor in our framework and a key motivator for career-interested users. Compared to other decision-related indicators, the number of job openings provides a clearly identifiable information that helps career-motivated users develop an objective insight into the current state of the job market. Such information will then facilitate the decision of career-motivated users on how much effort to exert in contribution-based signaling.

From a pure bargaining perspective, one might expect a negative effect of the number of job vacancies on the baseline relationship: more vacancies imply decreased competition among job seekers and greater bargaining power for them relative to recruiters, thereby reducing the need for signaling. As such, careerconcerned users may reduce their effort. However, from the cost-benefit based rational choice perspective, career-motivated users might actually increase their signaling effort in response to greater job availability. That is because the more jobs for a specific skill are available, the more attractive it will appear for an individual user to make investments in activities that may aid in obtaining a job. In fact, empirical investigations in traditional labor markets support a positive effect of job availability by showing that the market demand such as the number of available jobs has a positive effect on career decision-making such as job market entry and education degree attainment
$[15,16,44]$. This suggests that job vacancies are very likely to positively affect the signaling activities of career-concerned users.

This positive moderation of job vacancies is also consistent with the expectancy theory of motivation [41]. The theory, rooted in the question of career concern and job-related motivation [31,41], postulates the relationship between an individual's effort and the desirability of the individual's goal and the expected probability of goal achievement. The higher the desirability or the expectation of achieving it, the more effort the individual will exert [6]. Applying the expectancy theory of motivation to signaling in online collaboration communities suggests a positive effect of job vacancies on the baseline relationship. Careerconcerned users will intensify their signaling effort when the prospect of achieving their career goals appears higher (expectation increases). Thus, we expect that the association between a user's career concern and her contributions strengthens as the number of job vacancies increases.

Hypothesis 2 (H2): The number of job vacancies in the market positively moderates the relationship between a user's career concern and the user's contributions.

\subsection{Expected salary}

Similar to the number of job vacancies, the salary that a career-concerned user can expect from a job is a key moderator of the relationship between career concern and user contributions. For three reasons, we predict a positive influence of the expected salary on the baseline relationship. First, in general, there is a strong link between monetary incentives and human behavior [27], especially between expected income and career selection [15,38]. Second, job seekers can easily perceive and evaluate expected salary, and thus react to it. It is a straightforward criterion, which simplifies the comparison between different career alternatives, and hence it is likely to be used by the career-motivated users as a decision criterion. Third, compared to other job-decision criteria such as the location, size, or organizational structure of the employer, salary preferences are relatively homogeneous across individuals. All else equal, one would prefer more salary over less, whereas other preferences such as work location might vary widely among users. Because of these reasons, the expected salary is likely to exert a clearer effect than most other criteria.

Hypothesis 3 (H3): The expected salary from the available jobs positively moderates the relationship between a user's career concern and the user's contribution 


\subsection{Community-market transparency}

The third and final contingent factor in our framework is the information flow between community and the job market. We refer to this contingency as community-market transparency, which represents the ease of information flows between community users and external recruiters.

In general, transparency reduces the costs of transactions (for empirical evidence in financial markets, see [7,12]). Thus, we expect that in the context of online collaboration communities, greater transparency in the job-matching process should reduce frictions and search costs by improving information flows between the supply side (job seekers in the community) and the demand side (external recruiters). In several ways, community-market transparency benefits the job-seeking users in pursuing their career goals. Under greater transparency, these users can observe more and better information about opportunities in the job market. Community-market transparency also lowers the effective cost of sending signals, as it allows users to target selected employers instead of spreading their signaling effort across numerous targets. Morefocused signaling efforts on a select set of employers at a given cost allow the career-concerned users to produce more and/or higher-quality signals.

On the demand side, community-market transparency has several merits for external recruiters. They can more easily target the talent. Greater transparency means an improved quality of the signals, which helps recruiters better screen job candidates, thereby facilitating their hiring decisions. These benefits for recruiters, in turn, create positive feedback for the supply side of the market, encouraging more users to seek career opportunities through the community. Gains from greater market transparency will then draw more recruiters to the market. "Thick market externalities" $[11,18]$ may thus result: the job market becomes populated with more players on both sides, leading to a higher likelihood of matching between job seekers and recruiters and making both sides better off.

These benefits offered by community-market transparency suggest that career-motivated users will likely adjust their contribution level responding to the degree of transparency. Under greater transparency, any changes in the job market get transmitted to careermotivated users with less information loss. Likewise, with greater transparency, career-concerned users can expect their signals to more precisely reach recruiters. Hence, career-concerned users will find signaling through contributions to be more attractive in pursuing their career goals, thus increasing their contributions when community-market transparency is high.

Further support can be derived from a behavioral perspective as well as the expectancy theory of motivation [41], such as in H2. Greater communitymarket transparency increases the prospects of fulfilling career goals specifically because career-concerned users are more convinced that the signals they create in the online community can actually reach the intended audience (i.e., external recruiters). Without a clear path to these recruiters, users are less motivated to send a signal through contributions because there is little guarantee that the signal will reach the intended receiver. Thus, under low transparency, users' career motivation remains largely latent and users are less likely to consider contributions as opportunities to signal. This weakens the link between career concern and user contribution. However, with a clearer and more effective information channel in place, the community and the activities inside it become more visible to external recruiters. Realizing this will in turn boost the motivation of career-concerned users to send signals through increased contribution. Hence, the link between career concern and user contribution gets strengthened. That is, given the level of career concern, a greater level of contribution is better justified. Together, these reasons suggest that under greater community-market transparency, the association between career concern and user contribution will become stronger.

Hypothesis 4 (H4): Information transparency between the supply and demand sides of the job market (community-market transparency) positively moderates the relationship between a user's career concern and the user's contributions.

\section{Empirical design}

Our research context is Stack Overflow, a free and public online Q\&A platform for computer programming-related issues. Career concern is highly relevant for the users in this online collaboration communities. According to a survey of over 56,000 users, more than three-quarters of the respondents expressed interests in a programming-related career by indicating that they were either actively looking for a job (15.5\%) or open to new job opportunities (62.7\%).

Stack Overflow has a career service, "Stack Overflow Careers.” This service allows users to create a CV certifying their reputation scores. Paying recruiters can custom-search the CVs and list job advertisements. Thus, users can leverage their activities and reputation in the community as a signal and thus present themselves to potential employers. The community introduced this service in two stages. The initial version launched on (November 3, 2009) charged fees to both community users (a one-time \$25) and recruiters (amount undisclosed). In the subsequent version "Stack Overflow Careers 2.0" (launched on February 23, 
2011), Stack Overflow eliminated fees for community users. This change has considerably relaxed the users' constraint, making it much easier for them to use Stack Overflow Careers.

We believe that the introduction of Stack Overflow Careers has decidedly increased community-market transparency. Stack Overflow's original intention was to help users find better jobs, rather than to directly promote user contributions. With the career service platform in place, job-seeking users can much more efficiently signal their quality to the recruiters. In particular, they can directly target the employers and jobs that match their career goals. Likewise, recruiters can identify and access qualified candidates more easily and at considerably lower costs. Hence, the introduction of Stack Overflow Careers must have significantly enhanced the transparency of the job market relevant to the users in the online collaboration community.

We downloaded from the community's website the entire user activity data in Stack Overflow over a time period of 5 years, from the outset of the community to June 2013. The raw dataset contains 14,630,209 Q\&As written by 2,055,496 unique users. We also obtained job-market demand data from IT Jobs Watch, a company that maintains historical records of the IT job market in the U.K. The dataset contains quarterly data of the number of job vacancies and average salary offers for 113 programming languages from 2006 to 2015. Thus, each of these programming languages represents a segment of the IT job market. We only included users who contributed a total of at least 10 answers. The panel has 684,000 user-quarter observations of 72,444 users.

Our dependent variable should capture the level of user contribution. Users can contribute to the community by posting frequently, or making highquality posts, or both. However, quality is observed only when a user makes any post. Hence, we primarily measure user contribution by the count of posts. To construct Quantity of contribution, we counted the number of total posts that a user made in each quarter. Because a user can contribute to multiple knowledge domains (language and non-language) but our jobmarket data are specific to a programming language, we need to assign a primary language for each user-quarter observation. That way, we can precisely link the user response to demand changes in a specific programming language. Hence, we designated for each user-quarter the primary language based on his activity in the preceding four quarters.

We also considered Quality of contribution. For a given post, other community users can evaluate it by voting up $(+1)$ or down $(-1)$. The resulting score netting these votes indicates the overall perceived quality of a contribution. We thus constructed a quality measure using the sum of net votes for the contributions in each user-quarter.

Each of our four hypotheses requires an independent variable. For the baseline hypothesis (H1), we need a measure that captures the degree to which a user is interested in seeking a career. For this, we exploited the CVs posted on Stack Overflow Careers, which reveal two important pieces of information about users' career concern: whether a user has posted a CV to the site and what content the CV contains. We use the estimated level of effort to create a $\mathrm{CV}$ as a proxy for a user's career concern. All else equal, a longer CV will take more time and effort to put together and thus represent a greater level of career concern than a shorter CV. To construct the CV-based measure of career concern, we first searched the CVs of all users in our sample $(74,008)$. Of these, 34,007 users (46\%) have posted their CVs. We then constructed CV length by counting the number of words contained in each CV. This is our primary measure of the user's career concern. We assigned zero for the users with no CVs posted.

For testing H2, we captured the Number of job vacancies as the quarterly count of job advertisements for each programming language, compiled by the company IT Jobs Watch. For testing H3, we computed Expected salary as the quarterly average salaries offered for the permanent jobs in a given programming language, also collected by IT Jobs Watch. For the construction of Community-market transparency (H4), we exploited the introduction of Stack Overflow Careers. As discussed earlier, this career service promotes the information flow in both directions between community users and external recruiters. Recruiters can advertise job vacancies in a standardized format, which makes it easier for the users to find appropriate job postings. The service also improves the quality of the users' signaling of their skills. Reputation scores earned through knowledge contributions are available to recruiters, who can then compare across multiple candidates on a common standard. Stack Overflow Careers initially charged fees for both the users and the recruiters but later made it free for the users after some time. We chose to distinguish between before and after the elimination of user fees ("Stack Overflow Careers 2.0"), which decisively made the service popular within the community, and constructed a binary variable called Post to indicate low (0) and high (1) community-market transparency.

It is important to note that all the moderators representing the three contingent factors in our framework are exogenous to the community users. The number of vacancies and expected salaries are beyond the control of individual users and difficult to predict in a precise manner. The introduction of Stack Overflow Careers and the change of fees were also exogenous. 
Most of our control variables consist of a series of fixed effects to account for possible confounding influences from other covariates of contribution activity. To account for the time-invariant user-level unobserved heterogeneity, we included dummies for individual users. Also, because other job-market conditions and user contribution behavior may differ across programming languages, we included dummies for programming languages. Quarter dummies were included to account for possible temporal variations. Programming-language-fixed effects and quarter-fixed effects were included in all estimation models. However, testing $\mathrm{H} 1$ prevents us from including userfixed effects because our measure of career concern (CV length) is time-invariant within the user. Hence, when testing H1, we used a random-effects model. Users may vary in experience, which may confound the effect of CV length. Thus, we controlled for user experience by including community tenure, measured by the number of days since the user joined the community. To account for the possible heterogeneity in writing propensity across users, we included the average length of posts (time-invariant) for each user in random-effects models. This variable may also capture some of the heterogeneity across users in writing style (some users tend to write longer than others) and hence partially correct for the baseline inter-user differences in CV length. We log-transformed all continuous variables to reduce heteroskedasticity. We used Stata 15.

\section{Results}

Model 1 in Table 3 shows the relationship of career concern with the quantity of user contribution using the (log) number of posts as the dependent variable. Consistent with our baseline hypothesis (H1), the coefficient on CV length as a proxy for career concern is strongly positive (Model 1). The estimated elasticity (0.032) implies that doubling the length of posted user $\mathrm{CV}$ is associated with a $3.2 \%$ increase in the user's volume of contributions to the online community.

Models 2-6 include user-fixed effects, where CV length needed to be dropped due to it perfect collinearity with user fixed effects (CV length is time-invariant within user). In Model 3 we find a significant and positive interaction of CV length and Number of job vacancies showing that the career concern-user contribution relationship is positively moderated by the number of vacancies. The career-driven users contribute more frequently when there are more jobs in their programming language available in the market, which supports $\mathrm{H} 2$.
Table 1: Quantity of contribution

\begin{tabular}{|c|c|c|c|c|c|c|}
\hline & (1) & (2) & (3) & (4) & (5) & (6) \\
\hline $\begin{array}{l}(\log ) \# \text { of } \\
\text { days since } \\
\text { join }\end{array}$ & $\begin{array}{c}-0.356^{* *} \\
(0.004)\end{array}$ & $\begin{array}{c}-0.284^{* *} \\
(0.007)\end{array}$ & $\begin{array}{c}-0.284^{* *} \\
(0.007)\end{array}$ & $\begin{array}{c}-0.284^{* *} \\
(0.007)\end{array}$ & $\begin{array}{c}-0.284^{* *} \\
(0.007)\end{array}$ & $\begin{array}{c}-0.284^{* *} \\
(0.007)\end{array}$ \\
\hline $\begin{array}{l}\text { (Log) } \\
\text { Average } \\
\text { length of } \\
\text { posts }\end{array}$ & $\begin{array}{c}0.352 * * \\
(0.008)\end{array}$ & & & & & \\
\hline $\begin{array}{l}\text { (Log) CV } \\
\text { length }\end{array}$ & $\begin{array}{c}0.032 * * \\
(0.002)\end{array}$ & & & & & \\
\hline $\begin{array}{l}\text { (Log) \# job } \\
\text { vacancies }\end{array}$ & $\begin{array}{l}0.027 * \\
(0.011)\end{array}$ & $\begin{array}{l}0.027 * \\
(0.011)\end{array}$ & $\begin{array}{l}0.021+ \\
(0.011)\end{array}$ & $\begin{array}{l}0.027^{*} \\
(0.011)\end{array}$ & $\begin{array}{l}0.027^{*} \\
(0.011)\end{array}$ & $\begin{array}{l}0.023 * \\
(0.011)\end{array}$ \\
\hline $\begin{array}{l}\text { (Log) } \\
\text { Expected } \\
\text { salary }\end{array}$ & $\begin{array}{c}0.060 \\
(0.044)\end{array}$ & $\begin{array}{c}0.025 \\
(0.045)\end{array}$ & $\begin{array}{c}0.025 \\
(0.045)\end{array}$ & $\begin{array}{c}-0.036 \\
(0.048)\end{array}$ & $\begin{array}{c}0.024 \\
(0.045)\end{array}$ & $\begin{array}{c}-0.028 \\
(0.048)\end{array}$ \\
\hline $\begin{array}{l}(\mathrm{Log}) \mathrm{CV} \\
\text { length } \\
\times(\mathrm{Log}) \# \\
\text { job vacancies }\end{array}$ & & & $\begin{array}{c}0.004^{* *} \\
(0.001)\end{array}$ & & & $\begin{array}{c}0.003^{* *} \\
(0.001)\end{array}$ \\
\hline $\begin{array}{l}\text { (Log) CV } \\
\text { length } \\
\times(\mathrm{Log})\end{array}$ & & & & $\begin{array}{c}0.048^{* *} \\
(0.014)\end{array}$ & & $\begin{array}{c}0.041^{* *} \\
(0.014)\end{array}$ \\
\hline $\begin{array}{l}\text { Expected } \\
\text { Salary }\end{array}$ & & & & & & \\
\hline $\begin{array}{l}\text { (Log) CV } \\
\text { length } \\
\times \text { (Dummy) } \\
\text { Post }\end{array}$ & & & & & $\begin{array}{c}0.013^{* *} \\
(0.003)\end{array}$ & $\begin{array}{c}0.012^{* *} \\
(0.003)\end{array}$ \\
\hline Constant & $\begin{array}{c}0.610 \\
(0.508)\end{array}$ & $\begin{array}{c}3.046^{* *} \\
(0.523)\end{array}$ & $\begin{array}{c}3.053 * * \\
(0.524)\end{array}$ & $\begin{array}{c}3.053^{* *} \\
(0.522)\end{array}$ & $\begin{array}{c}3.059 * * \\
(0.523)\end{array}$ & $\begin{array}{c}3.069 * * \\
(0.524)\end{array}$ \\
\hline User FE & No & Yes & Yes & Yes & Yes & Yes \\
\hline Language FE & Yes & Yes & Yes & Yes & Yes & Yes \\
\hline Quarter FE & Yes & Yes & Yes & Yes & Yes & Yes \\
\hline $\mathrm{N}$ & 682710 & 682710 & 682710 & 682710 & 682710 & 682710 \\
\hline Within R2 & 0.102 & 0.103 & 0.103 & 0.103 & 0.103 & 0.103 \\
\hline
\end{tabular}

Note: The dependent variable in all models is the (log) number of posts received by the user in a given quarter. "Yes" or "No" indicates whether or not the corresponding fixed effects are included in the model. Robust standard errors, clustered by users, are in parentheses. +, *, ** denotes statistical significance at $10 \%, 5 \%$, and $1 \%$, respectively.

Model 4 tests the interaction between CV length and Expected salary. This interaction is significant and positive related to user contribution quantity, indicating that the career-driven users respond to a greater degree when the available jobs offer higher salaries. The firstorder effect of Expected salary is statistically insignificant as in other models. This suggests that any effect of expected salary on user contribution occurs only in conjunction with the user's career concern, consistent with our moderation hypothesis. Hence, we found support for $\mathrm{H} 3$.

In Model 5, we obtain a significantly positive coefficient on the interaction term between CV length and the Post. This supports H4, which predicts a positive moderation of community-market transparency on the career concern-user contribution relationship. Thus, we find evidence that career-motivated users contribute more frequently when information flows in the job market are under greater transparency. Considering all explanatory variables at once did not change the results (Model 6). 
Table 2: Quality of contribution

\begin{tabular}{|c|c|c|c|c|c|c|}
\hline & (1) & (2) & (3) & (4) & (5) & (6) \\
\hline $\begin{array}{l}\text { (Log) \# of } \\
\text { days since } \\
\text { join }\end{array}$ & $\begin{array}{c}-0.312^{* *} \\
(0.005)\end{array}$ & $\begin{array}{c}-0.271^{* *} \\
(0.009)\end{array}$ & $\begin{array}{c}-0.271^{* *} \\
(0.009)\end{array}$ & $\begin{array}{c}-0.271^{* *} \\
(0.009)\end{array}$ & $\begin{array}{c}-0.271^{* *} \\
(0.009)\end{array}$ & $\begin{array}{c}-0.271 * * \\
(0.009)\end{array}$ \\
\hline $\begin{array}{l}\text { (Log) } \\
\text { Average } \\
\text { length of } \\
\text { posts }\end{array}$ & $\begin{array}{c}0.439 * * \\
(0.010)\end{array}$ & & & & & \\
\hline $\begin{array}{l}\text { (Log) CV } \\
\text { length }\end{array}$ & $\begin{array}{c}0.034 * * \\
(0.002)\end{array}$ & & & & & \\
\hline $\begin{array}{l}\text { (Log) \# job } \\
\text { vacancies }\end{array}$ & $\begin{array}{c}-0.052^{* *} \\
(0.014)\end{array}$ & $\begin{array}{c}-0.053^{* *} \\
(0.015)\end{array}$ & $\begin{array}{c}-0.060 * * \\
(0.015)\end{array}$ & $\begin{array}{c}-0.053^{* *} \\
(0.015)\end{array}$ & $\begin{array}{c}-0.053^{* *} \\
(0.015)\end{array}$ & $\begin{array}{c}-0.058^{* *} \\
(0.015)\end{array}$ \\
\hline $\begin{array}{l}\text { (Log) } \\
\text { Expected } \\
\text { salary }\end{array}$ & $\begin{array}{l}0.144 * \\
(0.056)\end{array}$ & $\begin{array}{c}0.154^{* *} \\
(0.057)\end{array}$ & $\begin{array}{c}0.154^{* *} \\
(0.057)\end{array}$ & $\begin{array}{c}0.088 \\
(0.061)\end{array}$ & $\begin{array}{c}0.152^{* *} \\
(0.057)\end{array}$ & $\begin{array}{c}0.097 \\
(0.061)\end{array}$ \\
\hline $\begin{array}{l}\text { (Log) CV } \\
\text { length } \\
\times(\mathrm{Log}) \# \\
\text { job vacancies }\end{array}$ & & & $\begin{array}{c}0.005 * * \\
(0.002)\end{array}$ & & & $\begin{array}{l}0.004^{*} \\
(0.002)\end{array}$ \\
\hline $\begin{array}{l}\text { (Log) CV } \\
\text { length } \\
\times(\mathrm{Log})\end{array}$ & & & & $\begin{array}{c}0.052^{* *} \\
(0.019)\end{array}$ & & $\begin{array}{l}0.044 * \\
(0.019)\end{array}$ \\
\hline $\begin{array}{l}\text { Expected } \\
\text { Salary } \\
\text { (Log) CV } \\
\text { length } \\
\times \text { (Dummy) }\end{array}$ & & & & & $\begin{array}{c}0.014 * * \\
(0.004)\end{array}$ & $\begin{array}{c}0.012 * * \\
(0.004)\end{array}$ \\
\hline Post & & & & & & \\
\hline Constant & $\begin{array}{c}0.586 \\
(0.635)\end{array}$ & $\begin{array}{c}3.234^{* *} \\
(0.656)\end{array}$ & $\begin{array}{c}3.241^{* *} \\
(0.658)\end{array}$ & $\begin{array}{c}3.242 * * \\
(0.655)\end{array}$ & $\begin{array}{c}3.248 * * \\
(0.656)\end{array}$ & $\begin{array}{c}3.259 * * \\
(0.657)\end{array}$ \\
\hline User FE & No & Yes & Yes & Yes & Yes & Yes \\
\hline Language FE & Yes & Yes & Yes & Yes & Yes & Yes \\
\hline Quarter FE & Yes & Yes & Yes & Yes & Yes & Yes \\
\hline $\bar{N}$ & 678139 & 678139 & 678139 & 678139 & 678139 & 678139 \\
\hline Within R2 & 0.157 & 0.157 & 0.157 & 0.157 & 0.157 & 0.157 \\
\hline
\end{tabular}

So far, we have focused on the number of posts (Quantity of contribution) as a measure of user contributions. The other measure of user contribution is quality (Quality of contribution), which represents the usefulness of the contributions indicated by votes (from other users). From the perspective of an online collaboration community as a knowledge depository, promoting contents of high quality is perhaps equally, if not, more important than sheer quantity. Thus, posting high-quality content is also an effective way of signaling their skills to potential recruiters. Hence, in the next step, we look at the quality of user contribution and use the (log) number of votes received as the dependent variable (Table 2 ).

Models 1 through 6 in Table 2 replicate the corresponding models in Table 1 . The results are very similar to that in the analysis of contribution volume: Quality is strongly and positively associated with CV length (Model 1); and the interactions of CV length with the number of job vacancies (Model 3), expected salary
(Model 4), and the community-market transparency dummy (Model 5) are significantly positive in all models, including the full model (Model 6). Hence, the results suggest that career-motivated users respond to the market conditions by adjusting not only the frequency of their contribution but also the quality of the posts. This is reasonable because while the volume of contribution influences the visibility of a user in the community, it is the quality of contribution reflected in the reputation scores that determine the user's status. Hence, users with a greater career concern have a clear incentive to boost both the quantity and quality of contributions. Overall, our analysis of user contribution provides solid support for all hypotheses.

To improve the credibility in CV length as proxy for career concern, we developed two robustness checks. First, we distinguished between the types of user contribution by separately looking at user posting of questions versus user posting of answers to others' questions. This analysis tests whether the users who we consider as career-concerned optimize their signaling behavior by focusing on contributions that might promise more signaling gains (i.e., answers, not questions).The test clearly shows that answers are more sensitive to the CV length than questions (roughly three times as sensitive). This provides support for using CV length as a proxy for career concern. Second, in a similar way we divided user contributions into two categories: posts in programming-language domains and those in non-programming-language domains. If CV length is a proper proxy for career concern, we would expect to measure that career-motivated users concentrated their efforts on specific knowledge domains (i.e., programming languages) that might be more representative of their skills so as to better signal their skills to external recruiters. We found that the effects driven by $\mathrm{CV}$ length are stronger when it comes to programming-related contributions.

\section{Discussion}

Our results provide strong evidence for our framework on the conditions of career concern as a significant motivator of user contributions in online collaboration. We document systematic relationships between users' career interests, job-market demand indicators, transparency in information flow, and the quantity and quality of user contributions to the community. We first confirm a positive link between a user's career concern and the user's contributions $[26,36,43]$. Our analyses further show that changes in job-market demand conditions (number of vacancies and offered salaries) for a user-specific programming language skill positively moderate this career concernuser contribution relationship. Finally, we find that the 
increased community-market transparency, owing to the availability of Stack Overflow Careers, strengthens the positive relationship between career concern and user contribution.

\subsection{Contribution to theory}

Our study provides multiple implications for existing theory. We show that the motivating role of career concern is subject to market- and communitylevel contingencies, extending and improving on prior research that has primarily focused on the direct effect of career concern on user contribution [26,36,43]. Based on large-scale archival data, we validate career concern as a motivational driver. More importantly, we identify the contextual conditions that unleash career concern. Our framework on the contextual conditions of career concern builds on the human capital theory and labor market theory, which identified the number of open jobs and the expected salaries as positive influences of career choices $[15,16]$. In addition, the labor market literature indicates the importance of information transparency $[4,25]$. By demonstrating the relevance of these conditions for online collaboration communities, we introduce a contingency theory of career concern in online collaboration. Together, these three conditions account for a more complete and coherent picture of career concern as a motivational driver in online collaboration communities.

Our characterization of online collaboration communities as institutions for career concern has a strong implication for our understanding of the traditional institutions fulfilling that role. These institutions are the places of higher education, first and foremost the universities $[3,23,39]$. Comparing online collaboration communities to these traditional institutions prompts us to conjecture a possible paradigm shift in the configuration of signaling institutions. Traditionally, the function of the institutions of higher education is to certify the achievements of their "users" (i.e., students). Thus, they enable the students to signal their hidden skills and thereby improve their career prospects [3,39]. Our observations from Stack Overflow and the software developer job market suggest that online collaboration communities are also able to perform this role. Moreover, online collaboration communities even have a critical advantage over the institutions of higher education in fulfilling this role. The institutions of higher education contribute solely to the creation of the signal and the immediate outcome of the signal production process (i.e., exams and assignments) is usually wasted: "[S]tudents do work hard, because of reputation effects, even though it is entirely wasteful from a social point of view" [23:177]. In stark contrast, in online collaboration communities, the creation of the signal must provide an immediate benefit for other community users. Each contribution has at least one beneficiary (the asker of the question) and most often multiple beneficiaries, whose votes indicate the value they gain from the contributed content. In this way, the contribution's actual value is tightly coupled to the signal. Because of this coupling, we contend that online collaboration communities as institutions of career concern reduce the "waste" relative to the traditional signaling institutions. This represents a critical welfare advantage. Therefore, it might be that online collaboration communities can substitute the traditional institutions in their role as signal enablers for certain job-related qualities. This would mean a paradigm change with an impact on social welfare.

Another advantage of online collaboration communities as a signaling institution could be that inexperienced job-seekers could gain an easier entry to the job market. Because of the tight coupling between real-world values of the contribution and signal, online collaboration communities can help overcome the socalled career progression paradox, the problem that recruiters demand experienced job seekers but to acquire experience, the job seekers need a job [33].

Our study generalizes the role of career concern in user contribution beyond the context of open source software development, from which the original theory and literature of motivation by career concern emerged $[30,36]$. Our context differs from open source software development, which takes place in relatively more integrated organizations and handles more interrelated tasks such as coding, testing, and code integration [28]. Our context is based on flat structures [14] with virtually fully decomposable, atomic tasks. Nonetheless, our study also confirms the role of career motivation under these seemingly unfavorable conditions for pursuing career opportunities. Because online collaboration communities provide an arguably more conservative setting, we believe that our findings can be extended to the field of open source software development [30].

\subsection{Managerial implication}

We offer several implications for practitioners, especially managers and system designers of online collaboration communities. Perhaps the most important challenge for them is to attract and retain active users $[5,9,14,35]$. An effective way of achieving this is to enhance the transparency of career prospects by offering direct channels to potential employers. Our results indicate that enhancing community-market transparency boosts both the quantity and quality of user contributions to the community. Hence, instituting features that closer connect job-markets with the 
community and improve the information between them is a useful strategy. Associated improvements in content quality facilitated by better community-market transparency are another merit to utilizing this instrument. Therefore, for community administrators, increasing community-market transparency can be a relatively low-risk high-return strategy for promoting the success of their community.

Enhancing the community-market transparency is, of course, possible only if there are significant external career opportunities that demand for the knowledge and skills relevant to the community. For instance, for general Q\&A communities such as Answers.com and Quora, it seems difficult to define what the relevant job markets are and external job opportunities may hardly exist. For these communities, community-market transparency is probably irrelevant. However, there is a broad range of online collaboration communities that can utilize community-market transparency as a motivational instrument. For example, companies that build on input from communities, such as firms relying on community-based customer support [24] or those using ideas and knowledge produced in the community $[1,10,29]$, may well benefit from career-motivated participation and are able to create the right conditions to induce career-based motivation. The hosting companies themselves represent the demand side of the job market. Crucial for the hosting company in utilizing this hiring strategy is to offer well-payed jobs (corresponding to our variables, number of vacancies and expected salary) and most importantly, link career opportunities directly to contributions in the community and make this relationship clear to the community members thus increasing community-market transparency (corresponding to our variable with the same name).

\subsection{Limitations and future research}

Our study has several limitations as we discuss below, which provide interesting avenues for future research. First, our measure of career concern-CV length-is admittedly a crude measure, though this is our best attempt to quantify user career concern based on secondary data. It is also time-invariant, and hence conceals potential dynamics in the effect over time. This is because we do not know the exact timing of the $\mathrm{CV}$ posting. Thus, regardless of when the users posted their $\mathrm{CV}$ to Stack Overflow Careers, we treat them as if they were career-motivated from the time they appear in the dataset. However, it is entirely likely that users have posted their CVs only after they become interested in seeking careers, which may well be a while since they have been active in the community. It is also possible that after posting their CVs, some users have lost interest in seeking careers but left their CVs on the site. In either case, the actual link between CV length and contribution activity for these users will likely be weaker than assumed. Therefore, our estimate based on the time-invariant $\mathrm{CV}$ measure is likely to be a conservative one.

Second, our empirical strategy is not suitable for capturing potential interactions of career concern with other sources of motivation, especially those of intrinsic nature. We are not alone in facing this limitation; scholars have generally analyzed career motivation in isolation from other forms of motivation (exception is [36]). Further research incorporating different motivations and their interactions is needed.

Third, our job-market data cover only the U.K. Ideally, we would like to have region-specific data on jobs and salaries and match them with the users in the corresponding regions. Unfortunately, such data at the level of the precision of our data is not available. Though we find generally robust results on a narrower sample of EU users, caution may be necessary in applying the findings to the regions with IT labor markets that deviate considerably from that of the U.K.

\section{References}

[1] Afuah, A. and Tucci, C.L. Crowdsourcing as a Solution to Distant Search. Academy of Management Review, 37, 3 (2012), 355-375.

[2] Arazy, O., Nov, O., Patterson, R., and Yeo, L. Information Quality in Wikipedia: The Effects of Group Composition and Task Conflict. Journal of Management Information Systems, 27, 4 (April 2011), 71-98.

[3] Arrow, K.J. Higher Education as a Filter. Journal of Public Economics, 2, 3 (1973), 193-216.

[4] Autor, D.H. Wiring the Labor Market. Journal of Economic Perspectives, 15, 1 (2001), 25-40.

[5] Bateman, P.J., Gray, P.H., and Butler, B.S. Research Note: The Impact of Community Commitment on Participation in Online Communities. Information Systems Research, 22, 4 (2011), 841-854.

[6] Behling, O. and Starke, F.A. The Postulates of Expectancy Theory. Academy of Management Journal, 16, 3 (September 1973), 373-388.

[7] Bessembinder, $H$. and Maxwell, W. Markets: Transparency and the Corporate Bond Market. Journal of Economic Perspectives, 22, 2 (2008), 217-234.

[8] Butler, B.S., Bateman, P.J., Gray, P.H., and Diamant, E.I. An Attraction-Selection-Attrition Theory of Online Community Size and Resilience. MIS Quarterly, 38, 3 (2014), 699-728.

[9] Butler, B.S. Membership Size, Communication Activity, and Sustainability. Information Systems Research, 12, 4 (2001), 346-362.

[10] Chen, J., Xu, H., and Whinston, A.B. Moderated Online Communities and Quality of User-Generated Content. Journal of Management Information Systems, 28, 2 (2011), 237-268. 
[11] Diamond, P.A. Aggregate Demand Management in Search Equilibrium. Journal of Political Economy, 90, 5 (1982), 881-894.

[12] Edwards, A.K., Harris, L.E., and Piwowar, M.S. Corporate Bond Market Transaction Costs and Transparency. Journal of Finance, 62, 3 (2007), 14211451.

[13] Fang, Y. and Neufeld, D. Understanding Sustained Participation in Open Source Software Projects. Journal of Management Information Systems, 25, 4 (2009), 9-50.

[14] Faraj, S., Jarvenpaa, S.L., and Majchrzak, A. Knowledge Collaboration in Online Communities. Organization Science, 22, 5 (2011), 1224-1239.

[15] Flyer, F.A. The Influence of Higher Moments of Earnings Distributions on Career Decisions. Journal of Labor Economics, 15, 4 (October 1997), 689-713.

[16] Freeman, R.B. Supply and Salary Adjustments to the Changing Science Manpower Market: Physics, 19481973. American Economic Review, 65, 1 (1975), 27-39.

[17] Füller, J., Jawecki, G., and Mühlbacher, H. Innovation Creation by Online Basketball Communities. Journal of Business Research, 60, 1 (2007), 60-71.

[18] Gan, L. and Li, Q. Efficiency of Thin and Thick Markets. Journal of Econometrics, 192, 1 (2016), 40-54.

[19] Guo, S., Guo, X., Fang, Y., and Vogel, D. How Doctors Gain Social and Economic Returns in Online HealthCare Communities. Journal of Management Information Systems, 34, 2 (April 2017), 487-519.

[20] Hann, I.-H., Roberts, J.A., and Slaughter, S.A. All Are Not Equal. Information Systems Research, 24, 3 (2013), 520-538.

[21] Hara, N. and Hew, K.F. Knowledge-Sharing in an Online Community of Health-Care Professionals. Information Technology \& People, 20, 3 (2007), 235-261.

[22] Himanen, P. The Hacker Ethic and the Spirit of the Information Age. Random House Inc., New York, NY, 2001.

[23] Holmström, B. Managerial Incentive Problems: A Dynamic Perspective. Review of Economic Studies, 66, 1 (1999), 169-182.

[24] Jabr, W., Mookerjee, R., Tan, Y., and Mookerjee, V.S. Leveraging Philanthropic Behavior for Customer Support: The Case of User Support Forums. MIS Quarterly, 38, 1 (2014), 187-208.

[25] Kroft, K. and Pope, D.G. Does Online Search Crowd Out Traditional Search and Improve Matching Efficiency? Evidence from Craigslist. Journal of Labor Economics, 32, 2 (April 2014), 259-303.

[26] Lakhani, K.R. and Wolf, R.G. Why Hackers do What They do: Understanding Motivation and Effort in Free/Open Source Software Projects. In J. Feller, B. Fitzgerald, S. Hissam and K.R. Lakhani, eds., Perspectives on Free and Open Source Software. The MIT Press, Cambridge, MA, 2005, pp. 3-21.

[27] Lazear, E.P. Performance Pay and Productivity. American Economic Review, 90, 5 (2000), 1346-1361.
[28] Lee, G.K. and Cole, R.E. From a Firm-Based to a Community-Based Model of Knowledge Creation. Organization Science, 14, 6 (2003), 633-649.

[29] Leimeister, J.M., Huber, M., Bretschneider, U., and Krcmar, H. Leveraging Crowdsourcing: ActivationSupporting Components for IT-Based Ideas Competition. Journal of Management Information Systems, 26, 1 (July 2009), 197-224.

[30] Lerner, J. and Tirole, J. Some Simple Economics of Open Source. Journal of Industrial Economics, 50, 2 (2002), 197-234.

[31] Lynd-Stevenson, R.M. Expectancy-value theory and predicting future employment status in the young unemployed. Journal of Occupational and Organizational Psychology, 72, 1 (March 1999), 101-106.

[32] Nov, O. What Motivates Wikipedians? Communications of the ACM, 50, 11 (2007), 60-64.

[33] O’Mahony, S. and Bechky, B.A. Stretchwork: Managing the Career Progression Paradox in External Labor Markets. Academy of Management Journal, 49, 5 (2006), 918-941.

[34] Raymond, E.S. The Cathedral and the Bazaar: Musings on Linux and Open Source by an Accidental Revolutionary. O’Reilly, Sebastopol, CA, 1999.

[35] Ren, Y., Harper, F.M., Drenner, S., et al. Building Member Attachment in Online Communities: MIS Quarterly, 36, 3 (2012), 841-864.

[36] Roberts, J.A., Hann, I.-H., and Slaughter, S.A. Understanding the Motivations, Participation, and Performance of Open Source Software Developers: A Longitudinal Study of the Apache Projects. Management Science, 52, 7 (2006), 984-999.

[37] Seidel, V.P. and Langner, B. Using an Online Community for Vehicle Design: Project Variety and Motivations to Participate. Industrial and Corporate Change, 24, 3 (2015), 635-653.

[38] Siow, A. Occupational Choice under Uncertainty. Econometrica, 52, 3 (May 1984), 631-645.

[39] Spence, M. Job Market Signaling. Quarterly Journal of Economics, 87, 3 (1973), 355-374.

[40] von Krogh, G., Haefliger, S., Spaeth, S., and Wallin, M.W. Carrots and Rainbows: Motivation and Social Practice in Open Source Software Development. MIS Quarterly, 36, 2 (2012), 649-676.

[41] Vroom, V.H. Work and Motivation. Wiley, 1964.

[42] Wasko, M.M. and Faraj, S. Why Should I Share? MIS Quarterly, 29, 1 (2005), 35-57.

[43] Xu, L., Nian, T., and Cabral, L. What Makes Geeks Tick? A Study of Stack Overflow Careers. Management Science, 66, 2 (August 2019), 587-604.

[44] Zarkin, G.A. Occupational Choice: An Application to the Market for Public School Teachers. The Quarterly Journal of Economics, 100, 2 (May 1985), 409.

[45] Zhao, L., Detlor, B., and Connelly, C.E. Sharing Knowledge in Social Q\&A Sites: The Unintended Consequences of Extrinsic Motivation. Journal of Management Information Systems, 33, 1 (2016), 70-100. 